\title{
Exploring the Opening up of Service Industry and the Innovation and Development of Service Trade
}

\author{
Wenyong Li Xueyu Zhang \\ Huali College, Guangdong University of Technology, Guangzhou, Guangdong, 511325 \\ Email: 747317364@qq.com \\ Wenyong Li
}

Keywords: service industry, opening to the outside world, service trade, development and innovation

\begin{abstract}
With the development of economic globalization and the improvement of China's international status, China's service industry's open trade development and innovation research has become a new proposition of China's economic development in recent years, and has been widely concerned by the national economic construction departments and the community. However, due to the wide scope of service industry development, its opening and innovation have affected the development of education, finance, medical care and culture in China. Therefore, how to expand the development of China's service industry more scientifically and rationally, in the innovation of service trade Breakthrough is the key to the progress of the development of China's service industry. This paper analyzes the open and innovative development mode of China's service industry from the perspective of its opening to the outside world, and hopes that this article can provide some help for the economic development of China's service industry.
\end{abstract}

\section{Introduction}

Expanding the opening up of the service industry and innovating service trade are of great significance for improving the overall development level of China's economy and expanding the development of the service industry. The development of the service industry has important strategic significance for attracting foreign investment, improving manufacturing and various economic developments. Examining the development of the service industry from the perspective of world economic development and China's economic status and future planning, and exploring the innovative development ideas will become a new starting point for the comprehensive development of China's economy.

\section{Expanding the Significance of Service Industry Opening to the Outside World and Service Trade Innovation}

\subsection{The strategic significance of opening up the service industry to the outside world}

After the international financial crisis, the liberalization of trade in services and the diversification of trade cooperation are the focus of a new round of international economic development. Based on the current trends in international trade rules and the status quo of the development of tertiary industries in various countries, expanding the degree of openness of China's service industry and innovating the development of service trade will help to enhance China's influence in the global economic and trade system. At the same time, through this increase in influence, China will gain more voice in the world economic system, which is extremely beneficial to China's economic development. In addition, at present, China's domestic economic structure is also in urgent need of adjustment. With the improvement of the national economy and the demand of the people for material life and service industry, the current market share of service-oriented consumption such as education, medical care and culture has gradually increased. Expanding the opening up of the service industry will effectively promote the economic development of China while improving the economic structure. It can be seen that expanding the opening up of the service industry will 
effectively promote the overall progress of China's economy and is of great significance to the strategic adjustment and optimization of China's economy in the global economic development.

\subsection{Characteristics of the opening up of the service industry}

\subsubsection{Increase in the trade surplus of emerging services}

Since China joined the WTO, it has maintained a steady growth in the total volume and scale of service trade from 2002 to $2017^{[1]}$. China's position in the global economic market continues to rise. By analyzing the changes in China's trade structure in recent years, we can find that the proportion of traditional transportation, tourism, business services and other services in the total amount of trade in services has gradually declined, while the export of technical emerging service industries such as consulting and electronic information has shown an upward trend. The increase in the trade surplus of services has made the service industry more open in recent years in the exploration of the potential of these two industries.

\subsubsection{The service industry's attraction for foreign investment}

With the changes in the world economic structure and China's economic development, foreign investors' investment in China's economy has gradually changed from manufacturing to service industry in recent years. Among them, the ability of knowledge-intensive industries to attract foreign businessmen is more prominent. The financial and insurance industry and the technology service industry have become the focus of foreign investment.

\subsubsection{Service industry has become the main force of China's foreign investment}

Based on the strategic development direction of China's "going out", China is also actively encouraging domestic enterprises to increase their foreign investment. By 2012, China has become the third largest foreign investor after the United States and Japan with a net foreign investment of 87.8 billion US dollars ${ }^{[2]}$. In China's foreign investment, the service industry, wholesale and retail and financial industry have become the three largest categories of foreign investment. As the main business of China's foreign investment, the service industry has effectively improved the speed of China's foreign economic development.

\section{Analysis of the Status Quo of China's Service Industry Opening}

Before we study how to expand the openness of our service industry and the innovative way of trade development, we should analyze the current situation of China's service industry opening to the outside world.

\subsection{International competitiveness of service trade needs to be improved}

Although China's service industry is currently booming, the unreasonable structure of service trade is more serious. The international competitiveness of China's service trade is still in a weak state of parity. Taking the data of 2013 as an example, at that time, China's total trade in goods could surpass the United States to become the world's largest trader of goods. China's trade in goods accounted for more than $12 \%$ of the world's total trade in goods, but service trade only accounted for about $6 \%$. From this data, China's trade in goods and services has not been able to promote each other's growth. The development of trade in services is relatively slow, and it is dominated by traditional services such as tourism and transportation, with fewer emerging services. Although this status quo has eased in recent years, the international competitiveness of China's service trade still needs to be further improved.

\subsection{The market rules of the service industry and the rationalization of the structure of using foreign capital need to be improved}

At present, China's service industry is beyond the scale of foreign capital utilization in the scale of foreign capital utilization. However, the unreasonable foreign investment industry in the service industry and the irrational regional structure are still serious. From the perspective of investment industry, foreign investment favors industries with high returns in the short-term, such as real estate and wholesale and retail. For the choice of investment areas, foreign capital is more inclined to 
invest in developed areas in eastern China, and less attention is paid to investment in the central and western regions ${ }^{[3]}$. Moreover, due to the strictness of the state's relevant investment policies on foreign investment, it is difficult for the service industry to obtain more effective investment in an environment with excessive investment restrictions. The openness of the service industry and the optimization and opening up of relevant investment policies have greatly affected the current foreign investment in China. However, while the service industry is open, how to effectively balance the open dividend and try to avoid the risks brought about by the opening of the service industry is also a serious problem facing the current opening up of the service industry market.

\subsection{The service industry is still in the initial stage of opening up, and it still needs to improve the influence of China's foreign investment}

As China has joined the WTO and has achieved better and better results in international trade and investment, China is also making continuous attempts to expand the types of foreign investment. In recent years, the service industry has become a major industry for China's foreign trade investment. However, due to the late opening of China's foreign trade, the foreign investment and influence of service industry and service trade are even thinner in international trade exchanges. Therefore, how to enhance the impact of China's foreign service industry by expanding the opening up of service industry and the development of innovative service trade The power and the right to speak have become an important issue that China's service industry needs to solve urgently in its external development.

\section{Research on the Opening-up of Service Industry and the Innovation and Development Method of Service Trade}

Faced with the problems faced by the above service industry in opening up and developing service trade, we can carry out innovative research on ideas and methods from the following three perspectives.

\subsection{Efficiently promote the reform of the management system of foreign capital, and explore the management model of negative list before entering the country}

In response to the entry of foreign capital, at least 77 countries in the world are implementing pre-entry national treatment plus a negative list of foreign investment management models. In order to construct the development of service trade in line with China's development needs and international investment rules, the application of the negative list management mode before entry is an inevitable choice. At present, China has adopted a method of decentralizing power and deepening the reform of the administrative examination and approval management system in foreign trade. The pre-entry negative list management mode is consistent with the current management content direction in China. If we can promote the reform of the foreign investment management system from this perspective, it will create a good development environment for the development of China's service industry, and will enable China to gain a favorable position in the international industry competition and gain new development vitality. China can use Shanghai, Shenzhen and other places as experimental bases to carry out the use of pre-entry management list management mode and improve the speed of China's foreign investment management system reform ${ }^{[4]}$. Once foreign capital and China's social capital have equal access to service industry development conditions, they will be able to attract more foreign investment into China's service industry and effectively promote the expansion of China's service industry.

\subsection{Relaxation of investment access requirements, play and improve the government's coordinated supervision mechanism}

With the development of electronic information technology and the advancement of Internet technology, the emerging service industry and new business models have expanded and advanced in the development of information technology such as cloud computing, big data, and Internet of Things. The realistic environment of this market provides an opportunity for China's service 
industry to expand its opening up. And with the development of the service industry, cross-border integration development has become a popular trend. Faced with this development status, we must first strengthen the reform of the monopoly service industry, maintain a orderly competition in the service industry market by establishing a sound and unified opening system, and allow the market to develop in a stable and harmonious manner ${ }^{[5]}$. In addition, it is necessary to appropriately relax the access requirements, but at the same time there is a need to achieve reasonable supervision of the development risks of cross-border integration of service trade. The government should strengthen supervision and cooperation in the service industry's opening-up policy, strengthen the supervision responsibility of the provinces and cities, establish a comprehensive foreign service trade supervision mechanism from enterprises to the government, and create a good development environment for the service industry opening up and trade expansion.

\subsection{Innovating the development of China's service trade by drawing on the ideas of opening up to other countries' service industries}

Learning from the open experience of other countries' service industry is an effective means to enhance the development and innovation of China's trade services. In reference, China can refer to the US service industry open system to optimize and reform localization. In the opening up of the service industry, the United States mainly promotes a free and open policy and gives foreign investors national treatment, which can effectively attract foreign investment. In addition, the United States has adopted different restrictions on different service industries in the opening up of the service industry, and established a "double insurance" access system. China can learn from this open thinking, implement differentiated access policies for different industries in the service industry, and open the service industry in different regions and provinces. It can also be based on the development of local service industry and local development needs. We will adjust the service trade policy to better attract foreign investment that meets the development needs of the local service industry, so as to increase the speed of opening up the service industry.

\section{Conclusion}

All in all, as a populous country, China has an innate human resource advantage in the development of the service industry. However, how to better expand the opening up of the service industry and optimize the innovation and development of service trade requires us to develop according to the international economic situation and China's actual development. Unremitting adjustments and efforts have been made to encourage more local enterprises to go global. More foreign-funded enterprises are coming in, which is the direction for the opening up of the service industry.

\section{Acknowledgment}

This research was financially supported by the Key Research Platforms and Scientific Research Projects of Guangdong Province in 2018 (Young Innovative Talents) "Based on the Openness of Service Industry and Service Trade Innovation in the Pearl River Delta of Dawan District, Guangdong, Hong Kong and Macao"(Grant NO. 2018WQNCX261) and the Key Research Platforms and Scientific Research Projects of Guangdong Province in 2018 (Young Innovative Talents) "Research on Incentive Mechanism of Innovation Ecosystem Based on Guangzhou New Energy Automobile Industry"(Grant NO.2018WQNCX257).

\section{References}

[1] Zhanqi Yao. The Impact of the Real Openness of Service Industry on the Competitiveness of China's Service Industry [J]. Journal of Beijing Technology and Business University (Social Science Edition), 2015, 30(6): 22-30.

[2] Jiechang Xia, Zhanqi Yao. China's service industry has been open for 40 years-gradual process, openness assessment and experience summary [J]. Research on financial issues, 2018 (4): 3-14. 
[3] Wei Liu. Spatial Pattern of China's Service Industry: Evolution, Trends and Suggestions [J]. Learning and Exploration, 2017(6): 121-126.

[4] Xiuling Jin, Yajuan Liu. Suggestions on the Open and Innovative Development of Dalian Service Industry [J]. Modern Business, 2016 (3): 94-95.

[5] Danlu Liu. Innovation and Productivity under the Condition of Service Industry Internationalization_-Based on the Research of China's Producer Service Enterprise Data [J].Journal of Nanjing University (Philosophy \& Humanities \& Social Sciences),2013,50(6): 40-51. 